\title{
Analysis of Phosphatidylinositol 3,4,5-Trisphosphates of PTEN Expression on Mammalian Cells
}

\author{
Nusrat Jahan ${ }^{1}$, Taeseong Park ${ }^{4}$, Young Hwan Kim ${ }^{4,5}$, Dongsun Lee ${ }^{1}$, Hackyoung Kim ${ }^{1}$, Kwangmo Noh ${ }^{3}$, \\ and Young Jun Kim ${ }^{1,2,3^{*}}$ \\ ${ }^{1}$ Department of Applied Biochemistry \\ ${ }^{2}$ Research Institute of Inflammatory Diseases and ${ }^{3}$ Nanotechnology Research Center, Konkuk University, Chung-ju 380-701, Korea \\ ${ }^{4}$ Division of Mass Spectrometry Research, Korea Basic Science Institute, Ochang 363-883, Korea \\ ${ }^{5}$ Graduate School of Analytical Science and Technology, Chungnam National University, Daejeon 305-764, Korea
}

Received July 22, 2013; Revised September 24, 2013; Accepted September 24, 2013

First published on the web September 30, 2013; DOI: 10.5478/MSL.2013.4.3.41

\begin{abstract}
The goal of this study is to find an experimental condition which enables us to perform enzymatic studies on the cellular behavior of PTEN (phosphatase and tensine homolog) through identification of molecular species of phosphatidylinositol 3,4,5trisphosphates and their quantitative analysis in a mammalian cell line using mass spectrometry. We initially exployed a two-step extraction process using $\mathrm{HCl}$ for extraction of phosphatidylinositol 3,4,5-trisphosphates from two mammalian cell lines and further analyzed the extracted phosphatidylinositol 3,4,5-trisphosphates using tandem mass spectrometry for the identification of them. We finally quantified the concentration of phosphatidylinositol 3,4,5-trisphosphates using internal standard calibration. From these observation, we found that HEK 293-T cells is a good model to examine the enzymatic behavior of PTEN in a cell, and the minimum amount of phosphatidylinositol 3,4,5-trisphosphates is more than 50 pmol for quantification in a mass spectrometer. These results suggest that the well-optimized experimental conditions are required for the investigation of the cellular PTEN in terms of the catalytic mechanism and further for the detailed identification of cellular substrates.
\end{abstract}

Keywords: Phosphoinositides, Lipidomics, PTEN, Mass Spectrometry, Enzymatics

\section{Introduction}

Phosphoinositides, the phosphorylated derivatives of phosphatidylinositol (PI) are negatively charged phospholipids. Phosphatidylinositol 3,4,5-trisphosphates, also known as PtdIns $(3,4,5) \mathrm{P}_{3} \mathrm{~s}, \mathrm{PI}(3,4,5) \mathrm{P}_{3} \mathrm{~s}$ or $\mathrm{PIP}_{3} \mathrm{~s}$ among the phosphoinositides are the most difficult to characterize due to their presence in low concentration into cell. ${ }^{1-3}$ Several evidences showed that $\mathrm{PIP}_{3} \mathrm{~s}$ principally were accumulated into cell in response to a variety of stimuli, such as growth factors and oxidative stress, where phosphatidylinositol 4,5-disphosphates $\left(\operatorname{PtdIns}(4,5) \mathrm{P}_{2} \mathrm{~s}\right.$ or $\left.\mathrm{PI}(4,5) \mathrm{P}_{2} \mathrm{~s}\right)$ are phosphorylated at 3 position of the inositol ring by the action of PI3-Kinase. ${ }^{4-8}$ $\mathrm{PIP}_{3} \mathrm{~S}$ act as an important secondary messenger in incorporating multiple intracellular signaling pathways and in adjusting a large range of cellular activities., ${ }^{2,5} \mathrm{PIP}_{3} \mathrm{~s}$ can activate the downstream signaling events, like cell motility, cell proliferation, cell growth and cell survival via recruiting downstream signaling molecules (PKB/Akt) containing pleckstrin homology (PH) domain. ${ }^{9,10}$ Several studies showed that natural oncogenic form of PI3-Kinases caused elevation in $\mathrm{PIP}_{3}$ levels, activation of Akt and tumor progression. ${ }^{8,11,12}$

\footnotetext{
*Reprint requests to Prof. Young Jun Kim
}

E-mail: ykim@kku.ac.kr
Some recent studies showed that $\mathrm{PIP}_{3} \mathrm{~s}$ were degraded by the two inositol phosphatases, SHIP (SH2-containing inositol phosphatase, dephosphorylates $\mathrm{PIP}_{3}$ at the 5 position to produce $\mathrm{PI}(3,4)-\mathrm{P}_{2}$ ) and PTEN (phosphatase and tensine homolog, hydrolyzes $\mathrm{PIP}_{3}$ at the 3-position to produce $\mathrm{PI}\left(4,5-\mathrm{P}_{2}\right) .{ }^{5,13,14}$ PTEN (phosphatase and tensine homolog deleted on chromosome ten)/MMAC (mutated in multiple advanced cancers) is a tumor suppressor gene located at $10 \mathrm{q} 23^{15,16}$, which encodes a $55 \mathrm{kDa}$ protein composed of 403 amino acids. ${ }^{13,15,16}$ PTEN protein contains the consensus motif of $\operatorname{HCXXGXXR(S/T)}$ found in all protein tyrosine phosphatases (PTPs). ${ }^{5}$ Studies on tumor cell line showed that certain mutated PTEN induced elevated levels of $\mathrm{PI}(3,4,5) \mathrm{P}_{3}$ and of Akt activity ${ }^{13,17,18}$, and the introduction of wild type PTEN reduced levels of both. ${ }^{18,19}$ In another study, it was found that PTEN inactivation by oxidative stress also caused an increase in cellular PtdIns $(3,4,5) \mathrm{P}_{3}$ levels. $^{20}$

Recently, characterization of $\mathrm{PIP}_{3} \mathrm{~s}$ has received great attention in the field of lipidomics due to their involvement in lipid related diseases. There are different methods to identify them in cell extracts including receptor displacement assays, metabolic labeling, and chromatographic separation of the radiolabeled products after deacylation, ${ }^{6,21-23}$ but these techniques are technically demanding and suffer some limitations. 
Use of mass spectrometry based lipidomics can overcome these technical limitations and improve the detection process without previous separation through HPLC or TLC because of its high resolving power. Recently phosphatidylinositols were characterized in murine brain extracts using matrix-assisted laser desorption/ionization(MALDI)-time-of-flight(TOF) mass spectrometer(MS). ${ }^{24}$ Use of electrospray ionization (ESI)-MS also reported for phosphatidylinositol monophosphates (PIPs) and phosphatidylinositol diphosphates $\left(\mathrm{PIP}_{2} \mathrm{~s}\right)$ profiling in lipid extracts from cultured cells and rat brain ${ }^{3}$ and for PIPs, $\mathrm{PIP}_{2} \mathrm{~S}$ and $\mathrm{PIP}_{3} \mathrm{~s}$ in murine macrophage extracts. ${ }^{6}$

In the present study we searched experimental conditions to characterize molecular species of $\mathrm{PIP}_{3} \mathrm{~s}$ upon expression of PTEN protein in HeLa and HEK 293-T cell lines by using mass spectrometry. We initially found that more than $50 \mathrm{pmol}$ of $\mathrm{PIP}_{3} \mathrm{~S}$ are required for quantitation of them in a mass spectrometry and HEK 293-T cell is proper for study of cellular PTEN on enzymatic behavior in a cell. We recognized that the level of most of $\mathrm{PIP}_{3}$ s slightly reduced in HEK 293-T cells expressing of wild type PTEN protein and quantitatively increased in HEK-293T cells expressing of $\mathrm{C} 124 \mathrm{~S}$ mutant PTEN protein.

\section{Experimental Section}

\section{Chemicals and plasmid DNA}

Media and reagents for cell culture were obtained from WelGENE Inc. (Daegu, Korea), transfection reagents (Lipofectamine $^{\mathrm{TM}}$ LTX and PLUS ${ }^{\mathrm{TM}}$ Reagents) and OPTIMEM ${ }$ I Reduced Serum Medium from Invitrogen (San Diego, CA, USA). HA-probe (Y-11) and PTEN (FL-403) antibodies used as primary antibody in western blot were purchased from Santa Cruz Biotechnology, Inc. (Santa Cruz, CA, USA), BCA kits for protein concentration determination from Thermo Scientific. Standard phosphoinositides (PtdIns(1,2-dipalmitoyl) (ammonium salt), PtdIns-(3)-P (1,2dipalmitoyl) (ammonium salt), PtdIns-(4)-P (1,2-dipalmitoyl) (ammonium salt), PtdIns-(5)-P (1,2-dipalmitoyl) (ammonium salt), PtdIns-(3,5)- $\mathrm{P}_{2}$ (1,2-dipalmitoyl) (sodium salt), PtdIns$(3,4)-\mathrm{P}_{2}$ (1,2-dipalmitoyl) (sodium salt), PtdIns-(4,5)- $\mathrm{P}_{2}$ (1,2dipalmitoyl) (sodium salt), and PtdIns-(3,4,5)- $\mathrm{P}_{3}$ (1,2dipalmitoyl) (sodium salt)) and internal standards (PtdIns$(3,4,5)-\mathrm{P}_{3}$ (1,2-dipalmitoyl)- $\mathrm{d}_{62}$ (sodium salt)) were obtained from Cayman Chemical (Ann Arbor, MI, USA). Plasmid DNA pSG5L HA PTEN wt (ampR) and pSG5L HA PTEN C124S were purchased from Addgene (Cambridge, MA, USA).

\section{Cell culture and transfection}

HeLa and HEK 293-T cells were cultured in DMEM containing $10 \%$ fetal bovine serum, $100 \mathrm{U} / \mathrm{mL}$ penicillin and $100 \mu \mathrm{g} / \mathrm{mL}$ streptomycin and maintained at $37^{\circ} \mathrm{C}$ in a humidified atmosphere with $5 \%(\mathrm{v} / \mathrm{v}) \mathrm{CO}_{2}$. For a transfection, cells were plated in a $10 \mathrm{~cm}$ cell culture dish $24 \mathrm{~h}$ before a transfection. When cells were $50 \%$ to $80 \%$ confluent, transfection was performed using Lipofectamine ${ }^{\mathrm{TM}}$ LTX and
PLUS ${ }^{\mathrm{TM}}$ Reagents with Opti-MEM ${ }^{\circledR}$ I Reduced Serum Medium according to the manufacture's instruction.

\section{Phosphoinositdes extraction}

Phosphoinositides were extracted as described ${ }^{1,3,6}$ and slightly modified. Sample $\left(\sim 10^{7}\right.$ cells of 2 days after transfection) was transferred into $15 \mathrm{~mL}$ polypropylene centrifuge tube. $3 \mathrm{~mL}$ of ice-cold chloroform/methanol (1:2) containing $5 \mathrm{ng}$ of internal standard (PtdIns- $(3,4,5)-\mathrm{P}_{3}(1,2-$ dipalmitoyl)- $\mathrm{d}_{62}$ (sodium salt)) was added to centrifuged cell pellets. After vigorous vortexing, the sample was incubated on ice for $15 \mathrm{~min}$. Ice-cold chloroform $(1 \mathrm{~mL})$ was added, followed by phase splitting buffer $(1 \mathrm{~mL}$ of $1.76 \% \mathrm{KCl}$, $100 \mathrm{mM}$ citric acid, $100 \mathrm{mM} \mathrm{Na} 2 \mathrm{HPO}_{4}, 5 \mathrm{mM}$ EDTA, and $5 \mathrm{mM}$ tetrabutyl ammonium hydrogen sulphate, $\mathrm{pH}$ 3.6) to induce a phase-split. After mixing, the sample was incubated on ice for $5 \mathrm{~min}$. To complete the phase-split the sample was centrifuged ( $200 \mathrm{x} \mathrm{g}, 5 \mathrm{~min})$. The lower, organic phase was transferred into a clean tube. The upper, aqueous phase was reextracted with $2 \mathrm{~mL}$ synthetic lower phase $(150 \mu \mathrm{L}$ of water, $2 \mathrm{~mL}$ of $0.25 \mathrm{M}$ methanolic acid, $4 \mathrm{ml}$ of chloroform, and $1.5 \mathrm{~mL}$ of phase splitting buffer) and centrifuged ( $200 \mathrm{x} \mathrm{g}, 5 \mathrm{~min}$ ) and the resultant lower phase combined with the previous lower phase extract. $0.88 \% \mathrm{KCl}(2 \mathrm{~mL})$ was added to the remaining aqueous phase prior to extraction with $2 \mathrm{~mL}$ water-saturated butanol (30 min incubation on ice). The resultant butanol-rich upper phase was combined with the previous lower phase extracts. After drying, the sample was reextracted using $800 \mu \mathrm{L}$ of chloroform/methanol (1:1) and $500 \mu \mathrm{L}$ of $0.4 \%$ acetic acid. The solvent from the collected lower layer was evaporated in a vacuum centrifuge and resuspended in $50 \mu \mathrm{L}$ of chloroform/methanol/isopropanol (with ammonium acetate $5 \mathrm{mM})(1: 2: 4)$.

\section{Protein determination and western blot}

Protein expression was analyzed by western blotting. A $10 \mathrm{~cm}$ culture dish of transfected cells was collected by centrifugation at $500 \mathrm{x}$ g for $5 \mathrm{~min}$, washed with phosphate buffered saline (PBS). After 30 min incubation at $-80^{\circ} \mathrm{C}$, the cells were lysed in RIPA buffer supplemented with protease inhibitor and phosphatase inhibitor cocktail $1 \& 2$ (Sigma Aldrich Korea), and then vortexed for $15 \mathrm{~min}$, and cell lysates were centrifuged at $14,000 \mathrm{xg}$ for $10 \mathrm{~min}$ to remove insoluble material. Protein concentration was determined by BCA assay. Protein samples were prepared by boiling lysates in reducing SDS-sample buffer for $5 \mathrm{~min}$. Proteins were separated by $12.5 \%$ SDS-PAGE, and blotted to nitrocellulose transfer and immobilized membrane. The blotted membranes were blocked with $3 \%$ nonfat dry milk in TBS-T buffer (10 mM Tris, $150 \mathrm{mM} \mathrm{NaCl}, 0.2 \%$ Tween$20, \mathrm{pH} 8.0$ ). The membrane was probed with an appropriate primary antibody for overnight at $4^{\circ} \mathrm{C}$ and subsequently probed with secondary antibody for $1 \mathrm{~h}$. Immunoreactive bands were visualized using a chemiluminescence kit from Amershan Bioscience Co. (Piscaraway, NJ, USA). 


\section{Mass spectrometry}

Mass spectral analysis was performed on SYNAPT® G2 High Definition MSTM System with Q-TOF technology (Waters Corporation, MA, USA). The instrument was equipped with NanoMate (Advion, NY, USA), as an electrospray source. Samples were analyzed at an infusion rate of $20 \mu \mathrm{L} / \mathrm{min}$ in negative ionization mode over the range of $\mathrm{m} / \mathrm{z} 50-1,500$. The ion spray voltage was set at $-1.2 \mathrm{kV}$ and the source temperature was $80^{\circ} \mathrm{C}$. Data were collected with the MassLynx ${ }^{\mathrm{TM}}$ application managers (Waters Corporation MA, USA).

\section{Results and Discussion}

\section{PTEN expression on mammalian cells}

The main target of this study is to measure quantitative variation of $\mathrm{PIP}_{3}$ species which have different combination of fatty acid chain, among the wild type PTEN and mutant type PTEN expressing cells. In this regard we transfected HeLa and HEK 293-T cells with wild and mutant type (C124S) plasmid DNA each. To check the PTEN expression we performed western blotting probing with appropriate antibodies (HA and PTEN antibody) (Figure 1). The western blot images in HeLa cells showed that wild type PTEN expressed a little less than C124S mutant PTEN and transfected PTEN was in a more amount than endogenous

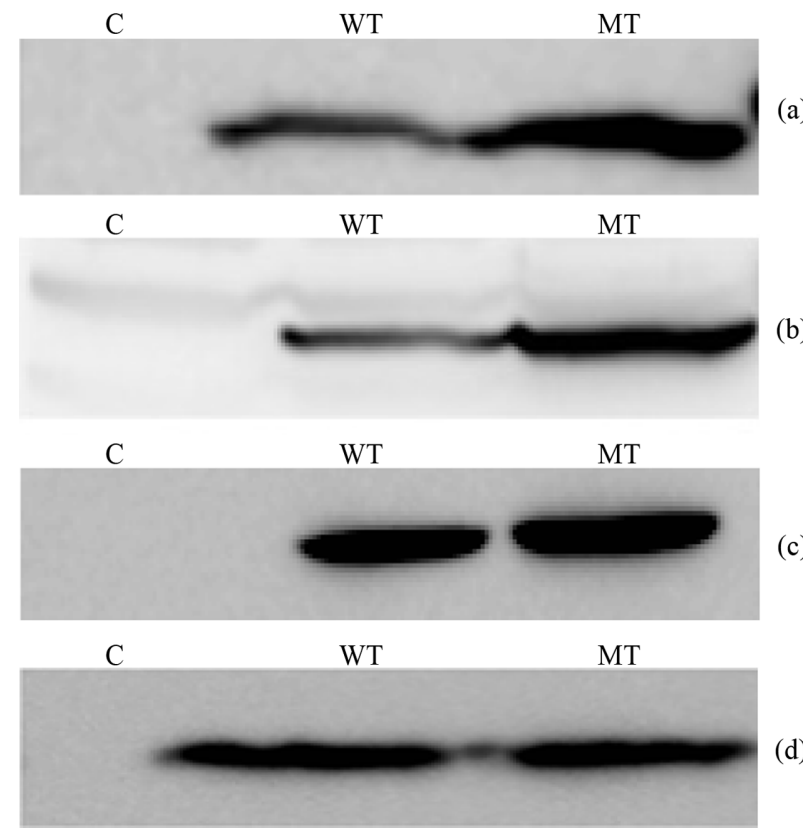

Figure 1. Western blot images of wild and mutant type PTEN expression in HeLa and HEK 293-T cell line. (a) Probed with HA antibody (HeLa cell), (b) Probed with PTEN antibody (HeLa cell), (c) Probed with HA antibody (HEK 293T cell line) and (d) Probed with PTEN antibody (HEK 293T cell line). C, control; WT, wild type; and MT, mutant type.

(c)
PTEN in both mutant and wild type expressing cells. The western blot images in HEK 293-T cells showed that both
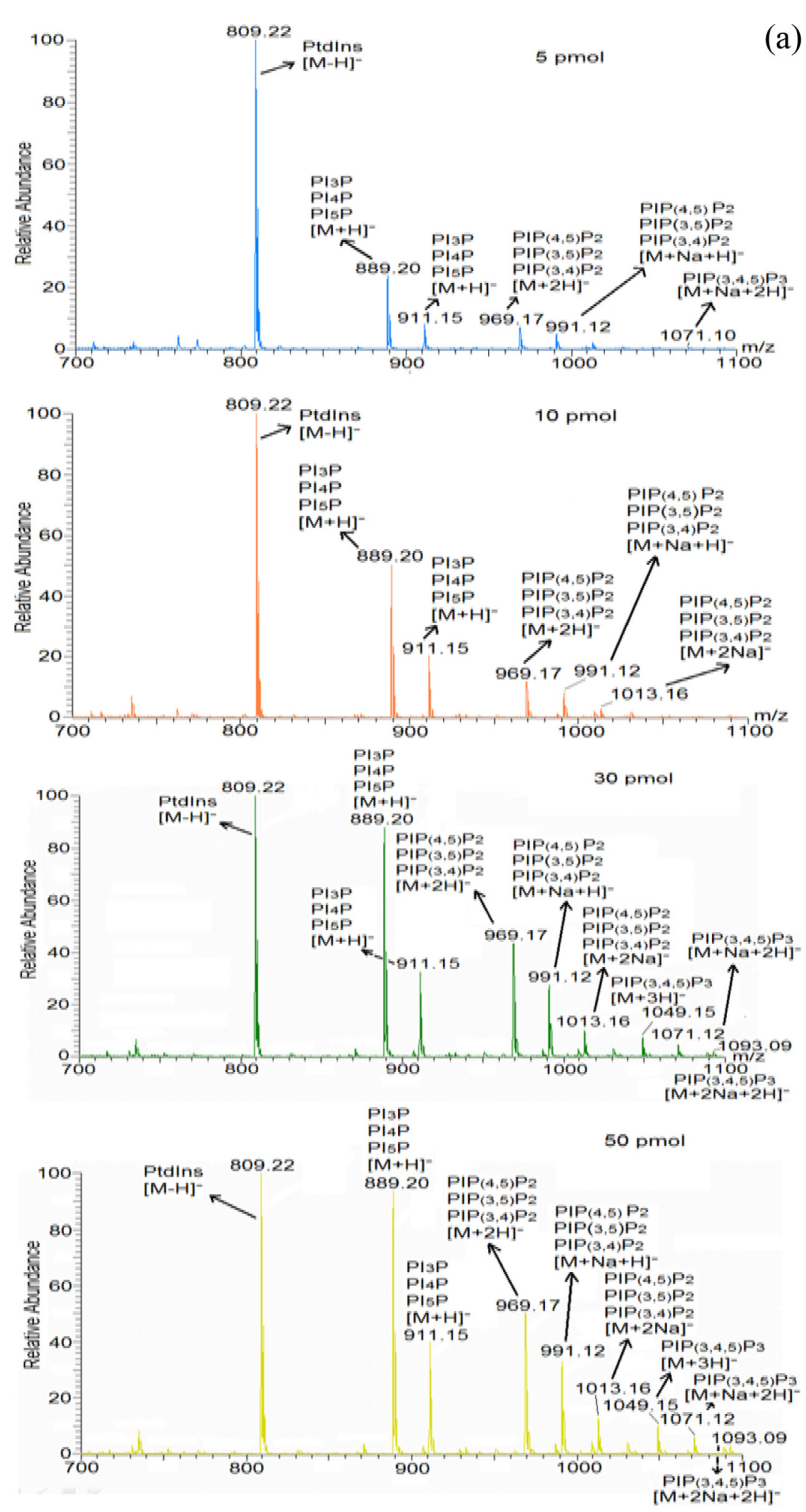

$$
\begin{aligned}
& \underbrace{\mathrm{O}_{5}}_{\mathrm{OR}^{4}} \\
& \text { naturally occurring: } \mathrm{R}^{1}=\mathrm{C}_{17} \mathrm{H}_{35}, \mathrm{R}^{2}=\mathrm{C}_{19} \mathrm{H}_{31} \\
& \begin{array}{ll}
\text { PI: } R^{3}=R^{4}=R^{5}=H & \text { PI(3,4)P2: } R^{3}=R^{4}=P O(O H)_{2}, R^{5}=H \\
\text { PI(3)P: } R^{3}=P O(O H)_{2}, R^{4}=R^{5}=H & \text { PI(3,5)P2: } R^{3}=R^{5}=P O(O H)_{2}, R^{4}=H \\
\text { PI(4)P: } R^{3}=H, R^{4}=P O(O H)_{2}, R^{5}=H & P I(4,5) P 2: R^{3}=H, R^{4}=R^{5}=P O(O H)_{2} \\
\text { PI(5)P: } R^{3}=R^{4}=H, R^{5}=P O(O H)_{2} & P I(3,4,5) P 3: R^{3}=R^{4}=R^{5}=P O(O H)_{2}
\end{array}
\end{aligned}
$$

Figure 2. Mass spectrometric data of phosphoinositide standards (a) and general chemical structure of phosphoinositides, which is adapted from ref. 25 with slight modification (b). 
wild type and C124S mutant PTEN expressed in a similar amount and endogenous PTEN was observed in a negligible amount. Based upon the different behavior of PTEN expression between HeLa and HEK 293-T cells, we thought that focusing on the lipidomic analysis of $\mathrm{PIP}_{3} \mathrm{~S}$ in HEK 293$\mathrm{T}$ cells is decent because observing quantitative variation of $\mathrm{PIP}_{3}$ s needs measurement in a condition of the same amount of enzyme between wild type and active site mutant.

\section{Mass spectrometric analysis of phosphoinositide standards}

To validate the sensitivity of the mass spectrometer in phosphoinositides' detection, mass spectrometric analysis of phosphoinositide standards (PI, PIP, $\mathrm{PIP}_{2}$ and $\mathrm{PIP}_{3}$ ) with different concentration was performed (Figure 2 (a)). The experiment showed the gradual increase of ion intensity of the phosphoinositide standards with their increased concentration. This suggests the lower limitation of detection of $\mathrm{PIP}_{3}$ using the mass spectrometric condition was found to be $\geq 50$ pmol for $\mathrm{PIP}_{3}$. Therefore, we found that required amount of PIP3s extracted from mammalian cells is at least 50 pmol in order to quantify molecular species of them. Based upon this observation, we checked the change of $\mathrm{PIP}_{3} \mathrm{~s}$ ' amount with different numbers of extracted cells (data not shown) and found that the minimum number of extracted cells is more than $10^{7}$ so as to quantify the $\operatorname{PIP}_{3}$ s. Additionally we provided general chemical structure of phosphoinositides in Figure 2 (b) for clear understanding of their mass spectrum.

\section{Mass spectrometric analyses of phosphoinositides extracted from mammalian cells}

To verify the effect of transfected PTEN on cellular $\mathrm{PIP}_{3} \mathrm{~s}$, phosphoinositides' were extracted from the transfected mammalian cell lines (HeLa cell and HEK 293-T cell) and subjected to the mass spectrometry analyses. We followed a 2 step extraction method of $\mathrm{PIP}_{3} \mathrm{~s}$ from cell based on phase splitting using $\mathrm{HCl}$. In order to confirm if $\mathrm{PIP}_{3} \mathrm{~s}$ are extracted in a proper way, we checked recovery amount of $\mathrm{PIP}_{3}$ with $\mathrm{PIP}_{3}$ standard $(50 \mathrm{pmol})$ through extraction process of this experiment and found that more $95 \%$ of $\mathrm{PIP}_{3}$ standard was recovered through comparing the intensity of it in a mass spectrum before extraction and after extraction (data not shown). Relatively higher numbers of mass peaks were observed in mass spectrum of PIPs extracted from HeLa cell (Figure 3 (a)) than them extracted (a)

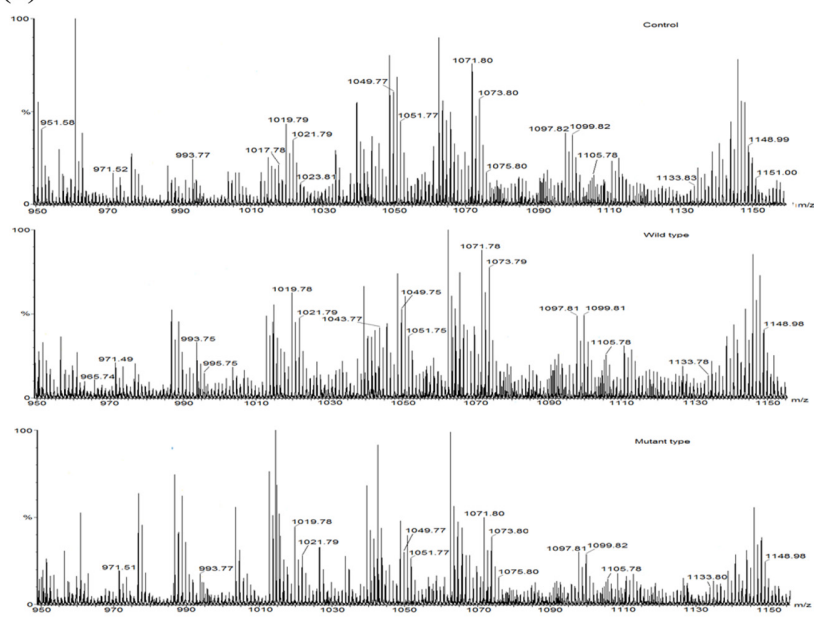

(b)

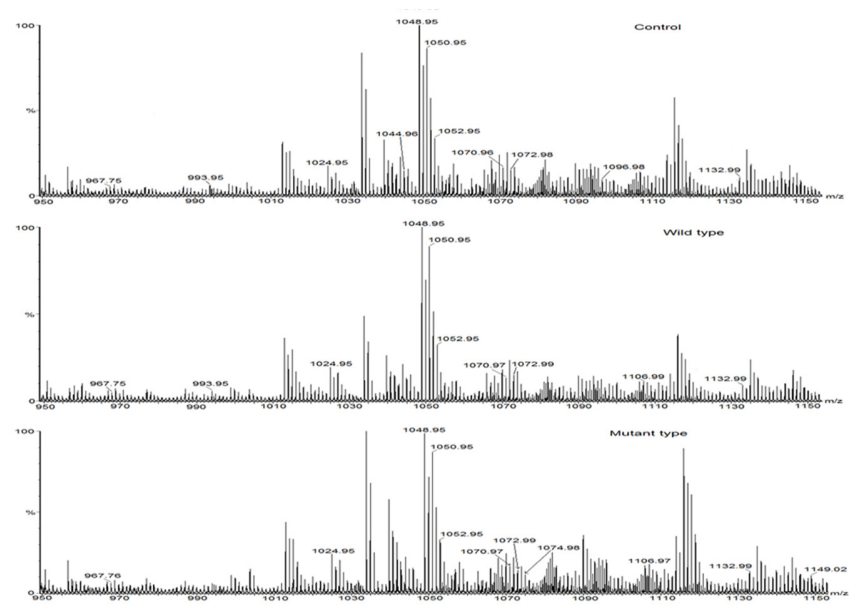

(d)

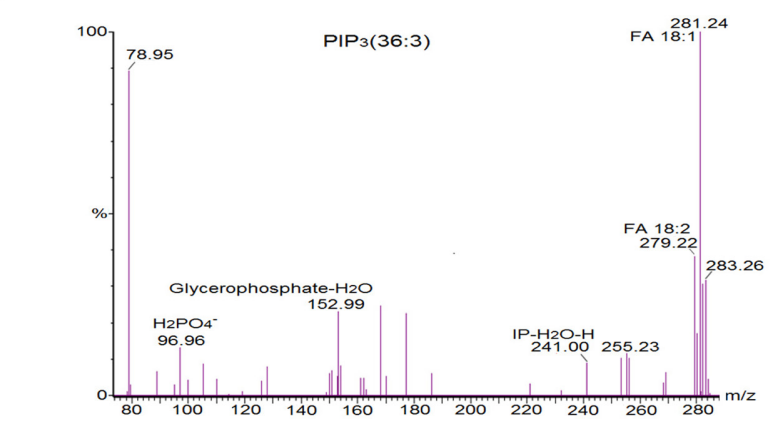

(c)

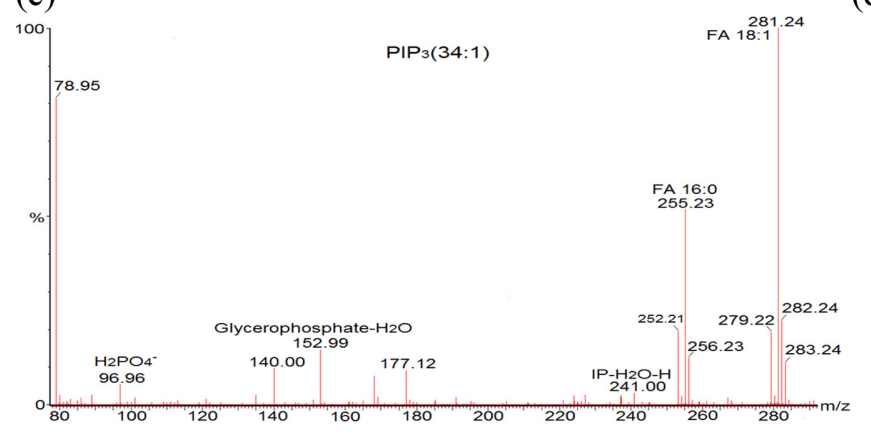

Figure 3. Representative mass spectrum ( $a, b)$ and MS/MS analysis (c, d) of phosphoinositides extracted from (a) HeLa cell line and (b) HEK 293-T cell line. (c) $\mathrm{PIP}_{3}$ (34:1) was identified at m/z 1075.80 and (d) $\mathrm{PIP}_{3}$ (36:3) was identified at m/z 1099.81 . 
from HEK 293-T cell (Figure 3 (b)) due to more complex composition of extracted lipids in HeLa cell line. We tried to identify $\mathrm{PIP}_{3}$ s from this mass spectrum through MS/MS analysis, and found that a certain number of $\mathrm{PIP}_{3} \mathrm{~S}$ which further were quantified through internal standard calibration. MS/MS analysis was performed so as to confirm identity and fatty acid composition of $\mathrm{PIP}_{3} \mathrm{~s}$. MS/MS spectra (Figure 3. (c) and (d)) of $\operatorname{PIP}_{3}(34: 1)$ and $\operatorname{PIP}_{3}(36: 3)$ among them of identified $\mathrm{PIP}_{3} \mathrm{~S}$ were representatively presented here. MS/MS analysis of the precursor ion peak at $\mathrm{m} / \mathrm{z} 1075.80$ was visibly assigned as $\operatorname{PIP}_{3}(34: 1)$. Two characterized fragments of the polar head group appeared at $\mathrm{m} / \mathrm{z} 241.00$ (inositolphosphate- $\mathrm{H}_{2} \mathrm{O}$ ) and $\mathrm{m} / \mathrm{z} 96.96$, which is from the $\left[\mathrm{H}_{2} \mathrm{PO}_{4}\right]^{-}$anion and one fragment of glycerol part was found at $\mathrm{m} / \mathrm{z} 153.00$ (glycerophosphate- $\mathrm{H}_{2} \mathrm{O}$ ). Two fatty acid fragments were identified at $\mathrm{m} / \mathrm{z} 281.20$, which corresponds to oleic acid 18:1, and at $\mathrm{m} / \mathrm{z} 255.20$, which corresponds to palmitic acid 16:0. Another characteristic phosphoinositide $\operatorname{PIP}_{3}(36: 3)$ was identified at $\mathrm{m} / \mathrm{z}$ 1099.82. Three characterized fragments from polar head group and glycerol part were appeared as above. Two fatty acid fragments were identified at $\mathrm{m} / \mathrm{z} 281.20$, which corresponds to oleic acid 18:1, and at $\mathrm{m} / \mathrm{z} 279.20$, which corresponds to linoleic acid 18:2.

\section{Quantitative analysis of PIP $_{3}$ s}

Quantitative study of the identified $\mathrm{PIP}_{3}$ s using a $\mathrm{PIP}_{3}$ internal standard showed the concentration of $\mathrm{PIP}_{3} \mathrm{~S}$ obtained from both HeLa and HEK 293-T cell in ng of lipid/mg of protein. We identified and quantified $7 \mathrm{PIP}_{3} \mathrm{~S}$ from both HeLa and HEK 293-T cell (Table 1). In case of HeLa cell, $\operatorname{PIP}_{3}(34: 1)$ and $\operatorname{PIP}_{3}(32: 0)$ were found in a higher concentration than other $\mathrm{PIP}_{3} \mathrm{~s}$, and the effect of both wild type and mutant PTEN expression showed strangely increasing concentration of all $\mathrm{PIP}_{3} \mathrm{~s}$ except $\mathrm{PIP}_{3}(34: 1)$. This strange behavior might be originated from difficult interference of endogenous PTEN behavior due to complicate circumstance of HeLa cell. In case of HEK 293$\mathrm{T}$ cell, $\mathrm{PIP}_{3}(32: 0)$ was found in a higher concentration that other $\mathrm{PIP}_{3} \mathrm{~s}$, and the concentrations of identified $\mathrm{PIP}_{3}$ s were higher in mutant type than wild type expressing cells since the functionally active PTEN can convert $\mathrm{PIP}_{3}$ to $\mathrm{PIP}_{2}$ by dephosphorylating at 3 position of the inositol head. Therefore, we conclude that HEK 293-T cell line is an appropriate system to study enzymatic behaviors of PTEN in a cell.

\section{Conclusion}

In conclusion, we found that in order to enzymatically study cellular activity of PTEN through mass spectrometry the extracted amount of $\mathrm{PIP}_{3} \mathrm{~s}$ should be more than $50 \mathrm{pmol}$, which is extracted from more than $10^{7}$ mammalian cells. Additionally, we found that HEK 293-T cell is proper to see enzymatic manner of PTEN in a cell. These results suggest that several experimentally optimized conditions are required for investigation of cellular PTEN on a catalytic mechanism and a detailed identification of cellular substrates. We will further investigate on more detailed identification of molecular species of cellular PIP $_{3} \mathrm{~s}$ based upon PTEN enzymatic activity in HEK 293-T cells with these optimized conditions and more experiments. In addition, we will study quantitative change of $\mathrm{PIP}_{3} \mathrm{~S}$ with differently expressed levels of PTEN in mammalian cells obtained through inducible expression system for kinetic study of cellular PTEN.

Table 1. Identified phosphatidylinositol 3,4,5-trisphosphates in HeLa and HEK 293-T cell line upon PTEN expression. ${ }^{\mathrm{a}}:$ ng of lipid/mg of protein, represents average \pm standard deviation from triplicate experiments

\begin{tabular}{|c|c|c|c|c|}
\hline & Identified $\mathrm{PIP}_{3} \mathrm{~S}$ & Control & Wild type & Mutant \\
\hline \multirow{7}{*}{$\mathrm{HeLa}$} & $\mathrm{PIP}_{3}(40: 5)$ & $57.2 \pm 3.5^{\mathrm{a}}$ & $72.7 \pm 28.5^{\mathrm{a}}$ & $87.6 \pm 24.0^{\mathrm{a}}$ \\
\hline & $\mathrm{PIP}_{3}(38: 1)$ & $17.4 \pm 3.2$ & $20.9 \pm 4.0$ & $22.3 \pm 5.8$ \\
\hline & $\mathrm{PIP}_{3}(36: 3)$ & $14.6 \pm 1.1$ & $14.8 \pm 3.3$ & $20.4 \pm 6.7$ \\
\hline & $\mathrm{PIP}_{3}(34: 1)$ & $80.8 \pm 2.4$ & $10.3 \pm 1.6$ & $15.4 \pm 5.2$ \\
\hline & $\mathrm{PIP}_{3}(34: 2)$ & $12.7 \pm 1.4$ & $15.8 \pm 3.0$ & $22.8 \pm 9.5$ \\
\hline & $\mathrm{PIP}_{3}(34: 3)$ & $18.2 \pm 2.6$ & $18.3 \pm 5.7$ & $30.5 \pm 14.1$ \\
\hline & $\mathrm{PIP}_{3}(32: 0)$ & $80.8 \pm 2.4$ & $66.8 \pm 22.7$ & $144.7 \pm 90.1$ \\
\hline \multirow{7}{*}{ HEK 293-T } & $\mathrm{PIP}_{3}(40: 6)$ & $53.7 \pm 5.4$ & $47.1 \pm 7.0$ & $56.5 \pm 3.2$ \\
\hline & $\mathrm{PIP}_{3}(38: 0)$ & $68.5 \pm 6.9$ & $46.3 \pm 24.2$ & $70.6 \pm 9.4$ \\
\hline & $\mathrm{PIP}_{3}(36: 3)$ & $51.2 \pm 9.3$ & $45.7 \pm 24.4$ & $56.6 \pm 3.8$ \\
\hline & $\mathrm{PIP}_{3}(34: 1)$ & $60.7 \pm 4.0$ & $51.8 \pm 30.6$ & $62.0 \pm 8.5$ \\
\hline & $\mathrm{PIP}_{3}(34: 2)$ & $86.1 \pm 14.7$ & $75.6 \pm 41.9$ & $82.0 \pm 10.0$ \\
\hline & $\mathrm{PIP}_{3}(34: 3)$ & $91.3 \pm 12.8$ & $65.6 \pm 38.7$ & $95.1 \pm 7.9$ \\
\hline & $\mathrm{PIP}_{3}(32: 0)$ & $589.0 \pm 194.0$ & $489.0 \pm 355.0$ & $552.0 \pm 82.0$ \\
\hline
\end{tabular}




\section{Acknowledgements}

This work was supported by the Basic Science Research Program (2010-0002609) through the National Research Foundation of Korea (NRF) funded by the Ministry of Education, Science, and Technology and by the Visiting Researcher Program in 2011 of Korea Basic Science Institute.

\section{References}

1. Vanhaesebroeck, B.; Leevers, S. J.; Ahmadi, K.; Timms, J.; Katso, R.; Driscoll, P. C.; Woscholski, R.; Parker, P. J.; Waterfield, M. D. Annu. Rev. Biochem. 2001, 70, 535.

2. Arendt, K. L.; Royo, M.; Fernandez-Monreal, M.; Knafo, S.; Petrok, C. N.; Martens, J. R.; Esteban, J. A. Nat. Neurosci. 2010, 13, 36.

3. Wenk, M. R.; Lucast, L.; Di Paolo, G.; Romanelli, A. J.; Suchy, S. F.; Nussbaum, R. L.; Cline, G. W.; Shulman, G. I.; McMurray, W.; De Camilli, P. Nat. Biotechnol. 2003, 21,813 .

4. Stephens, L. R.; Jackson, T. R.; Hawkins, P. T. Biochim. Biophys. Acta 1993, 1179, 27.

5. Maehama, T.; Dixon, J. E. J. Biol. Chem. 1998, 273, 13375.

6. Milne, S. B.; Ivanova, P. T.; DeCamp, D.; Hsueh, R. C.; Brown, H. A. J. Lipid Res. 2005, 46, 1796.

7. Hawkins, P. T.; Jackson, T. R.; Stephens, L. R. Nature 1992, 358, 157.

8. Rameh, L. E.; Cantley, L. C. J. Biol. Chem. 1999, 274, 8347.

9. Lemmon, M. A. Traffic 2003, 4, 201.

10. Kashiwada, M.; Lu, P.; Rothman, P. B. Immunol. Res. 2007, 39, 194.

11. Chang, H. W.; Aoki, M.; Fruman, D.; Auger, K. R.; Bellacosa, A.; Tsichlis, P. N.; Cantley, L. C.; Roberts, T. M.; Vogt, P. K. Science 1997, 276, 1848.

12. Jimenez, C.; Jones, D. R.; Rodriguez-Viciana, P.; Gonzalez-Garcia, A.; Leonardo, E.; Wennstrom, S.; von Kobbe, C.; Toran, J. L.; L, R. B.; Calvo, V.; Copin, S. G.; Albar, J. P.; Gaspar, M. L.; Diez, E.; Marcos, M. A.;
Downward, J.; Martinez, A. C.; Merida, I.; Carrera, A. C. EMBO J. 1998, 17, 743.

13. Myers, M. P.; Pass, I.; Batty, I. H.; Van der Kaay, J.; Stolarov, J. P.; Hemmings, B. A.; Wigler, M. H.; Downes, C. P.; Tonks, N. K. Proc Natl Acad Sci. U S A 1998, 95, 13513.

14. Wang, X.; Gjorloff-Wingren, A.; Saxena, M.; Pathan, N.; Reed, J. C.; Mustelin, T. J. Immunol 2000, 164, 1934.

15. Li, J.; Yen, C.; Liaw, D.; Podsypanina, K.; Bose, S.; Wang, S. I.; Puc, J.; Miliaresis, C.; Rodgers, L.; McCombie, R.; Bigner, S. H.; Giovanella, B. C.; Ittmann, M.; Tycko, B.; Hibshoosh, H.; Wigler, M. H. Parsons, R. Science. 1997, 275, 1943.

16. Hlobilkova, A.; Knillova, J.; Bartek, J.; Lukas, J.; Kolar, Z. Biomed. Pap. Med. Fac. Univ. Palacky Olomouc Czech Repub. 2003, 147, 19.

17. Stambolic, V.; Suzuki, A.; de la Pompa, J. L.; Brothers, G. M.; Mirtsos, C.; Sasaki, T.; Ruland, J.; Penninger, J. M.; Siderovski, D. P.; Mak, T. W. Cell. 1998, 95, 29.

18. Lee, J. O.; Yang, H.; Georgescu, M. M.; Di Cristofano, A.; Maehama, T.; Shi, Y.; Dixon, J. E.; Pandolfi, P.; Pavletich, N. P. Cell. 1999, 99, 323.

19. Li, D. M.; Sun, H. Proc. Natl Acad Sci. USA. 1998, 95, 15406.

20. Leslie, N. R.; Bennett, D.; Lindsay, Y. E.; Stewart, H.; Gray, A.; Downes, C. P. EMBO J. 2003, 22, 5501.

21. Gray, A.; Van Der Kaay, J.; Downes, C. P. Biochem. J. 344 Pt. 1999, 3, 929.

22. Alter, C. A.; Wolf, B. A. Biochem. Biophys. Res. Commun. 1995, 208, 190.

23. Nasuhoglu, C.; Feng, S.; Mao, J.; Yamamoto, M.; Yin, H. L.; Earnest, S.; Barylko, B.; Albanesi, J. P.; Hilgemann, D. W. Anal. Biochem. 2002, 301, 243.

24. Kim, Y.; Shanta, S. R.; Zhou, L. H.; Kim, K. P. Exp. Mol. Med. 2010, 42, 1.

25. Conway S. J.; Gardiner J.; Grove S. J.; Johns M. K.; Lim Z. Y.; Painter G. F.; Robinson D. E.; Schieber C.; Thuring J. W.; Wong L. S.; Yin M. X.; Burgess A. W.; Catimel B.; Hawkins P. T.; Ktistakis N. T.; Stephens L. R.; Holmes A. B. Org. Biomol. Chem. 2010, 8, 66. 